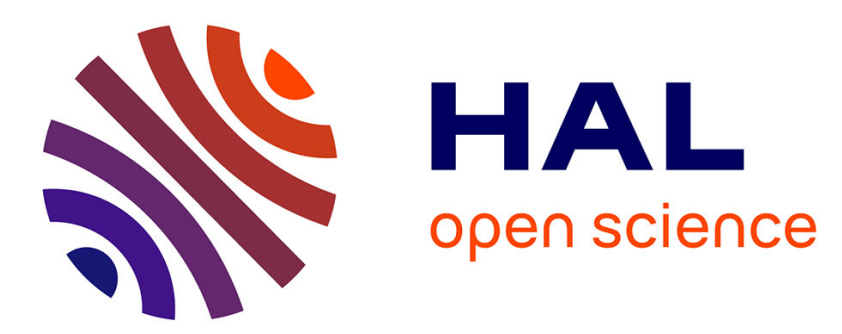

\title{
Calibration of an Active Ultrasound Bedload Monitoring System for Underwater Environments
} Gabriel Vasile, Guy d'Urso, Rayna Charlatchká, Elena Lungu

\section{To cite this version:}

Gabriel Vasile, Guy d'Urso, Rayna Charlatchká, Elena Lungu. Calibration of an Active Ultrasound Bedload Monitoring System for Underwater Environments. OCEANS 2015 - OCEANS '15 MTS/IEEE. Sea Change: Dive into Opportunity, Oct 2015, Washington, DC, United States. hal01257913

\section{HAL Id: hal-01257913 https://hal.science/hal-01257913}

Submitted on 19 Jan 2016

HAL is a multi-disciplinary open access archive for the deposit and dissemination of scientific research documents, whether they are published or not. The documents may come from teaching and research institutions in France or abroad, or from public or private research centers.
L'archive ouverte pluridisciplinaire HAL, est destinée au dépôt et à la diffusion de documents scientifiques de niveau recherche, publiés ou non, émanant des établissements d'enseignement et de recherche français ou étrangers, des laboratoires publics ou privés. 


\section{Calibration of an Active Ultrasound Bedload Monitoring System for Underwater Environments}

\author{
Gabriel Vasile \\ Grenoble-Image-sPeech-Signal-Automatics Lab \\ CNRS / Grenoble-INP, UMR 5216 CNRS \\ Grenoble Cedex, France, F-38402 \\ Email: gabriel.vasile@gipsa-lab.grenoble-inp.fr
}

Guy d'Urso

and Rayna Charlatchka

Électricité de France

EDF R\&D, STEP / LNHE, Chatou, France

Email: guy.durso@edf.fr controlled tank system.

\author{
Elena Lungu \\ SIGnal INformatics TEChnology \\ SIGINTEC \\ Grenoble, France, F-38100 \\ Email: elungu@ sigintec.fr
}

\begin{abstract}
This paper introduces the concept of coupling ultrasound transducers with piezoelectric accelerometers for active ultrasound bedload monitoring in underwater environments. A general system calibration procedure is proposed which allows the enduser to establish a real-time link between the energy of the received signals and the bedload transport phenomena.
\end{abstract}

\section{INTRODUCTION}

Monitoring the bedload transport in underwater environments is crucial for understanding stability issues such as reservoir silting or channel self-cleaning. In this context, sediment traps are widely used to derive the sediment balances. The Birkbeck sampler has become one of the preferred method for in situ bedload measurements [1]. Being an integral measure of the transported sediment volume in a certain time interval, this direct method suffers from one main drawback: it has a finite capacity. Without the use of devices such as a sludge pump to empty the accumulating sediment, the sampler fills and eventually ceases to yield data.

An alternative nonintrusive bedload monitoring instrument is the buried geophone station [2], [3], [4]. Under protection of steel plates, several geophones can provide continuous and automatic measurements, even during large floods. Every stone passing the steel geophone equipped plate generates an impulse recorded by the signal acquisition board. Using a calibrated voltage thresholding scheme the grain impacts are recorded and counted. One can notice that this instrument is highly sensitive to the environmental noise, since it is operating at low frequencies $(<1 \mathrm{KHz})$.

In [5], Bogen and Moen used piezoelectric acoustic transducers for bedload monitoring stations in Norway. The reported results present a clear correspondence with the sediment flow, but no estimation scheme is proposed.

In this paper, the potential of ultrasound (US) transducers coupled with piezoelectric accelerometers for bedload monitoring stations is further explored in a controlled laboratory environment. The main objectives are:

- to increase the operating frequency of the acoustic transducers,

- to provide consistent calibration and processing,

- to evaluate the uncertainty of the derived measurements.
To pursue these objectives, an experimental platform, illustrated in Fig. 1-(a) has been developed and tested in a

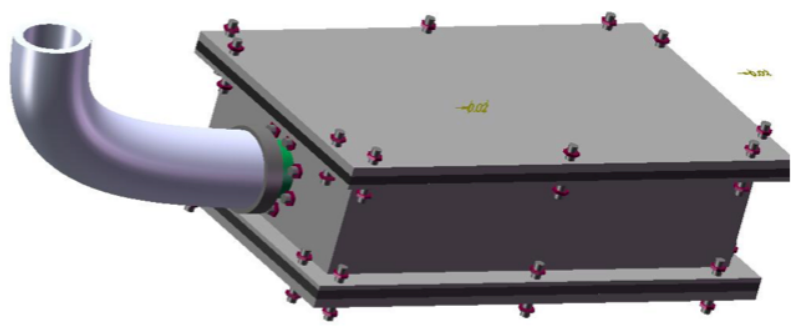

(a)

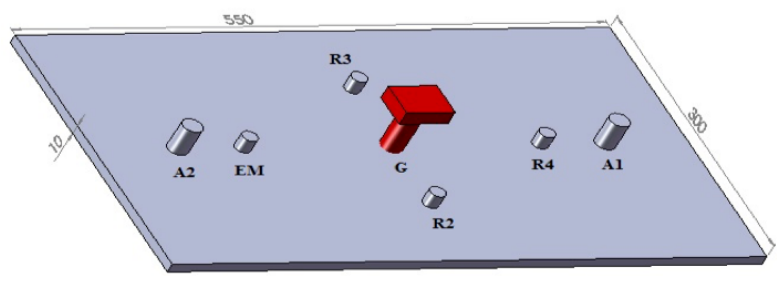

(b)

Fig. 1. Multi-sensor bedload monitoring platform: (a) general view, (b) setup of the acoustic sensors on the top steel plate.

\section{Calibration And meAsurement}

As illustrated in Fig. 1-(b), the following sensors have been employed: 4 ultrasound contact transducers PAC R50 (EM, R2, R3, R4), 2 calibrated piezoelectric accelerometers Endevco 233E (A1, A1) and 1 geophone R.T. Clark (G). The EM US transducer has been excited using the ENI 2100L power amplifier and the Picotest G5100A arbitrary signal generator. The received signals from A1, A2, R3, R4 have been conditioned using the Nexus low noise amplifier and recorded using the PXIe-1082 NI system. For the active configuration, the multi-sensor platform has been calibrated both in static and dynamic regimes.

The static calibration is a direct relationship between the output and the input of the system determined experimentally. Static calibration requires a reference standard, to which the output is reported. For our system of sensors, the calibration 
process determines a relationship between the input voltage controlling the EM US transducer and the output characteristic, called static characteristic curve or calibration. Fig. 2 shows the static characteristic in water, measured by transmitting a sinusoid signal and looking at the reception of the peak value of the Fourier transform. The value obtained supports the idea that our system is linear in all cases. In circumstances where the assumption of stationary is unsustainable, linear dynamic models need to be replaced by more sophisticated models. The linear theory provides a point of departure for such developments.

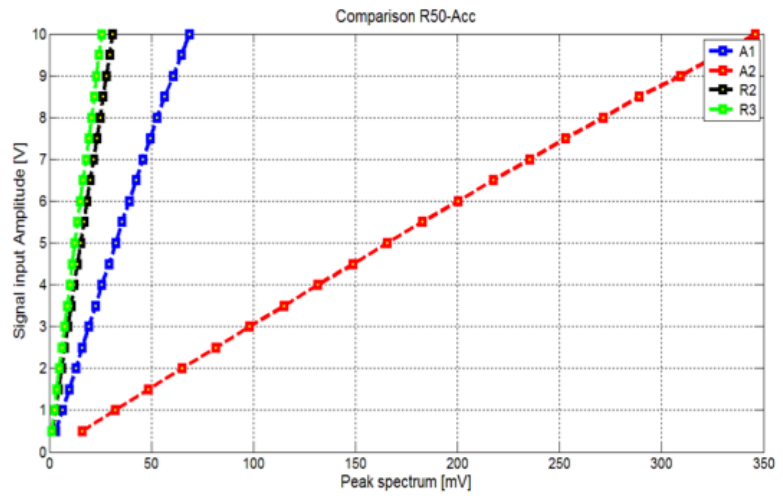

Fig. 2. Multi-sensor bedload monitoring platform: static characteristics.

The dynamic characteristic of each sensor is related to the performance when the input EM voltage signal is a function of time. The speed of response of a system refers to the ability to respond to sudden changes in the amplitude of the input signal. Thus, the response rate is calculated based on the parameters describing the system performance under the transition: constant measuring of the time delay (latency measurement), setup time (settling time), the dead time and range dynamics.

For a second order system, the transfer function can generally be expressed as:

$$
G(s)=\frac{Y(s)}{X(s)}=\frac{b_{0}}{a_{2} s^{2}+a_{1} s+a_{0}},
$$

where the $X(s)$ and $Y(s)$ are the Laplace transforms of the input and output signals.

The received signal characterizing the two transducers types are illustrated in Fig. 3 One can notice that the system settling time of the two accelerometers is greater than the settling time of the two ultrasound transducers. As a consequence, the triggering signal is set to be the signal received from the two accelerometers.

To obtain the performance parameters of a second order system, one can apply the Hilbert transform in order to retrieve the envelope of the received signal. According to Fig. 4, the important parameters are:

1) the payback period $\left(T_{d}\right)$ - time between two consecutive peaks after exceeding
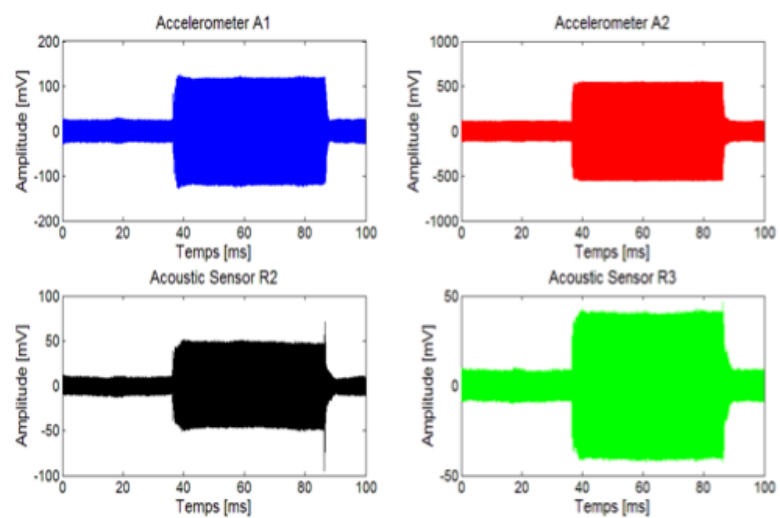

Fig. 3. Multi-sensor bedload monitoring platform: step response.

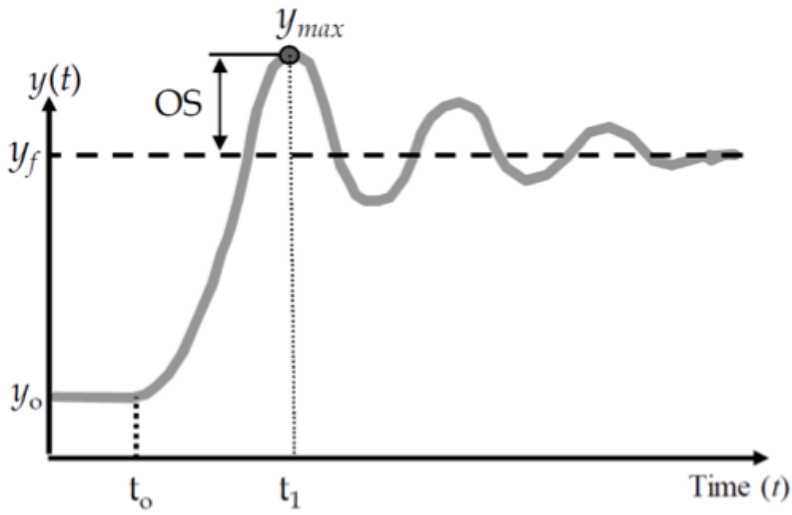

(a)
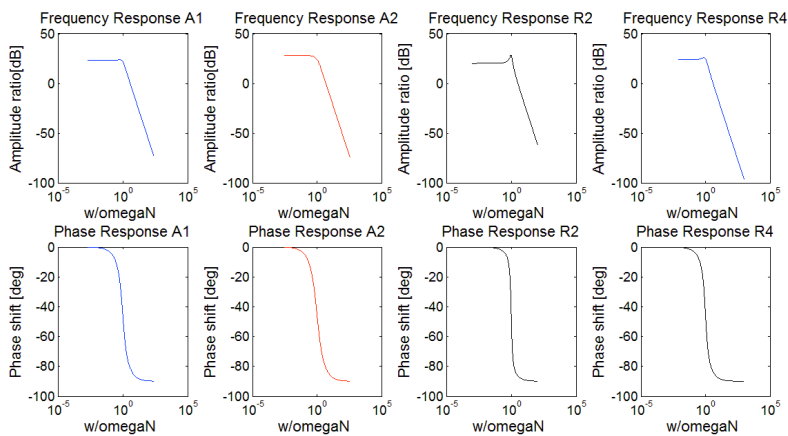

(b)

Fig. 4. Multi-sensor bedload monitoring platform: (a) step response parameters, (b) resulting frequency response.

2) the overshoot $(O S)$ - difference between the maximum signal value and the final value

$$
O S=y_{\text {max }}-y_{\text {fin }}=\left(y_{f i n}-y_{0}\right) e^{-\frac{\xi \pi}{\sqrt{1-\xi^{2}}}},
$$

3) the depreciation rate $(\xi)$ - describes how fast the signal is stabilized

$$
\frac{\xi}{\sqrt{1-\xi^{2}}}=\frac{1}{\pi} \ln \left(\frac{y_{f i n}-y_{0}}{O S}\right)
$$


4) the natural damping frequency $\left(\omega_{n}\right)$

$$
\omega_{d}=\frac{2 \pi}{T_{d}}=\omega_{n} \sqrt{1-\xi^{2}}
$$

5) the static sensitivity $(K)$ - difference between the amplitudes of the received signal before and after the settling time

$$
K=\frac{y_{f i n}-y_{0}}{C-C_{0}} .
$$

The obtained dynamic characteristic are illustrated in Fig. 5 and match the previously derived static characteristic.

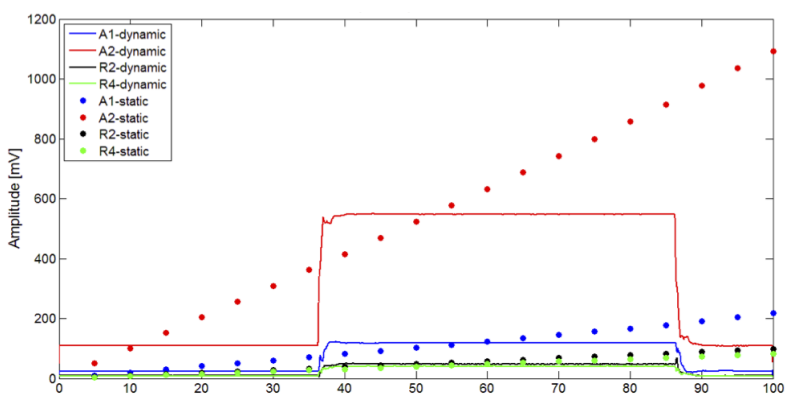

Fig. 5. Multi-sensor bedload monitoring platform: dynamic characteristics.

Finally, the transfer function of an acoustic transducer can be computed by positioning two transducer elements in transmission configuration:

1) by continuous excitation of one transducer with wide band white Gaussian noise, the other responds in its nominal frequency band.

2) by considering the performance parameters illustrated in Fig. 4-(b), one can define an impulsive excitation for estimating the system transfer function. Accordingly, by taking the impulse duration (short sine waveform) to be smaller than the system stabilization time, the transducer is sensing this calibration signal as an impulse and not as a step function.

In this paper, the second method for estimating the transfer function is employed and the results are illustrated on Fig. 6.

\section{RESULTS}

Four configurations have been tested in the controlled water tank facility :

- passive configuration in the nominal bandwidth of the impact $(<14 \mathrm{KHz})$,

- passive configuration outside the nominal bandwidth of impact (20 to $40 \mathrm{KHz}$ ),

- active configuration with continuous sine excitation at 21 $\mathrm{KHz}$,

- active configuration with chirp excitation at (20 to 40 $\mathrm{KHz}$ ).

After using controlled steel balls for calibration, two types of sediments were investigated and confidence intervals for the mass measurements have been obtained. Notice that the maximum speed in water have been reached before hitting the multi-sensor bedload monitoring platform in all cases. An

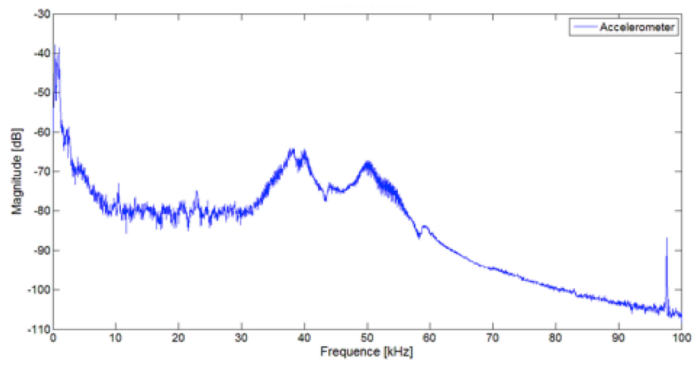

(a)

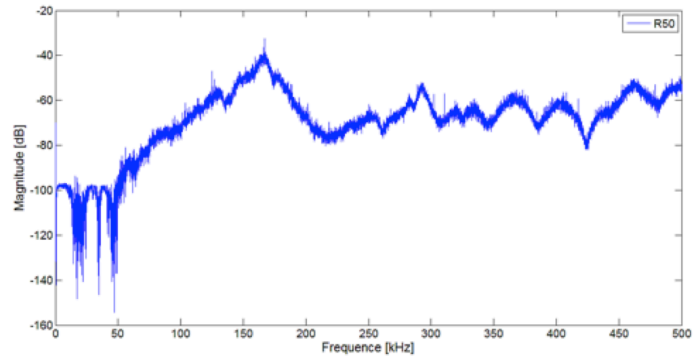

(b)

Fig. 6. Transducer transfer function: (a) accelerometer, (b) ultrasound transducer.

example of spectrogram of the received signals for steel ball calibration is illustrated on Fig. 7.
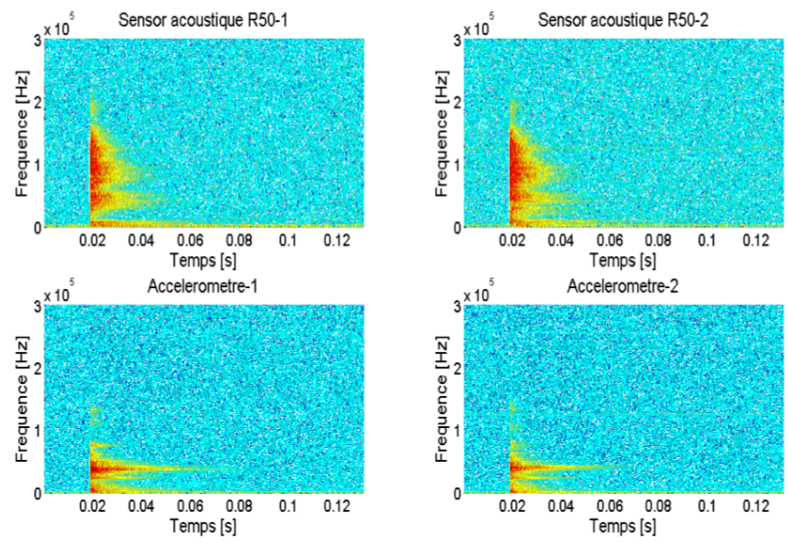

Fig. 7. Multi-sensor bedload monitoring platform: spectrogram of the received signals for steel ball calibration.

Figs. 8, 9, 10 and 11 illustrate the obtained results.

One can observe that the active ultrasound bedload monitoring platform can provide similar results (in terms of measurement error and confidence intervals) as conventional passive bedload monitoring in controlled noise free environment. This opens a new opportunity to increase the robustness of bedload monitoring system in underwater environments, where the frequency bands below $15 \mathrm{KHz}$ are quite sensitive to the environmental noise.

\section{CONCLUSION}

The general system calibration procedure presented in this paper offers an alternative option to monitor bedload transport phenomena in underwater environments. The main advantage 

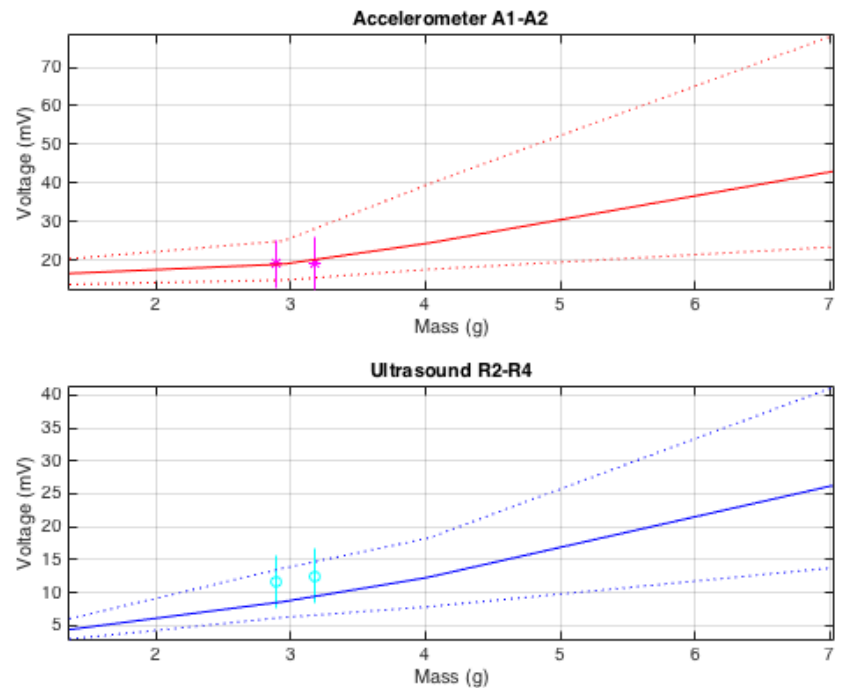

Fig. 8. Bedload mass measurements with passive configuration in the nominal bandwidth of the impact $(<14 \mathrm{KHz})$.
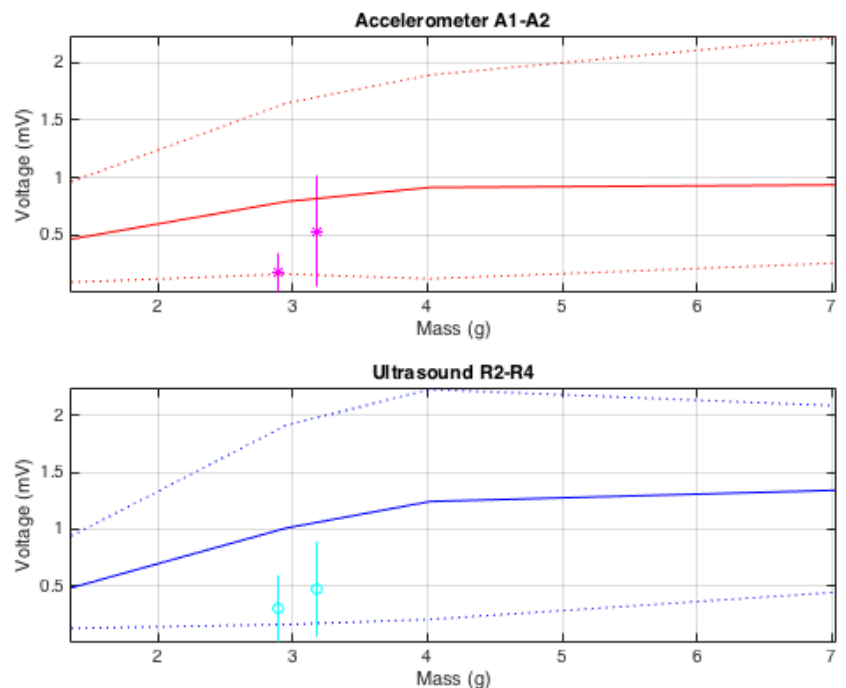

Fig. 9. Bedload mass measurements with passive configuration outside the nominal bandwidth of impact (20 to $40 \mathrm{KHz}$ ).

of the proposed experimental setup is better noise robustness at lower acoustic frequency bands. Future studies include the full performance analysis in real underwater conditions.

\section{ACKNOWLEDGMENT}

The authors would like to thank the Électricité de France company for funding this research.

\section{REFERENCES}

[1] J. B. Laronne, Y. Alexandrov, N. Bergman, H. Cohen, C. Garcia, H. Habersack, D. M. Powell, and I. Reid, The continuous monitoring of bedload flux in various fluvial environments, vol. 283, International Association of Hydrological Sciences Publication, 2003.
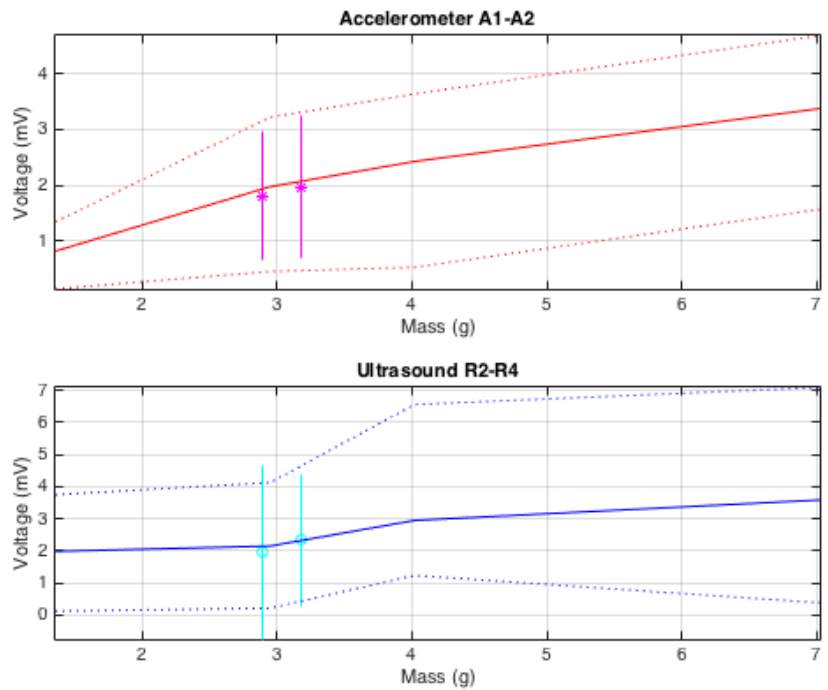

Fig. 10. Bedload mass measurements with active configuration with continuous sine excitation at $21 \mathrm{KHz}$.
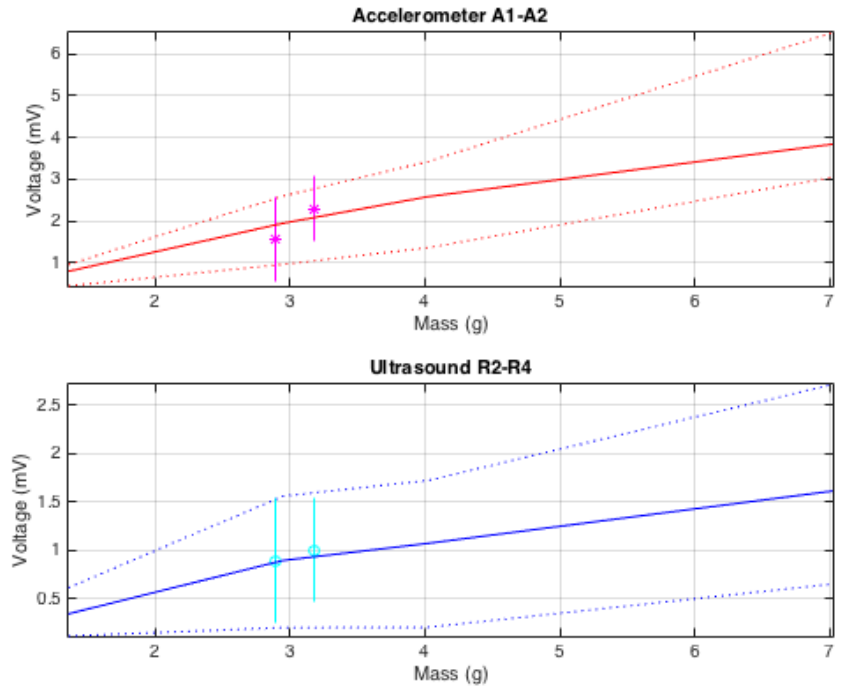

Fig. 11. Bedload mass measurements with active configuration with chirp excitation at (20 to $40 \mathrm{KHz})$.

[2] D. Rickenmann, J. M. Turowski, B. Fritschi, A. Klaiber, and A. Ludwig, "Bedload transport measurements at the Erlenbach stream with geophones and automated basket samplers," Earth Surface Processes and Landforms, vol. 37, no. 9, pp. 1000-1011, 2012.

[3] D. Rickenmann, J. M. Turowski, B. Fritschi, C. Wyss, J. B. Laronne, R. Barzilai, I. Reid, A. Kreisler, J. Aigner, H. Seitz, and H. Habersack, "Bedload transport measurements with impact plate geophones: comparison of sensor calibration in different gravel-bed streams," Earth Surface Processes and Landforms, vol. 39, no. 7, pp. 928-942, 2014.

[4] R. Hilldale, W. Carpenter, B. Goodwiller, J. Chambers, and T. Randle, "Installation of impact plates to continuously measure bed load: Elwha river, Washington, USA,” J. Hydraul. Eng., vol. 141, no. 3, pp. 06014023, 2015.

[5] J. Bogen and K. Moen, "Bedload measurements with a new passive acoustic sensor," in Erosion and Sediment Transport Measurement in Rivers: Technological and Methodological Advances, 2003, pp. 181-192. 